\title{
The Pore Characteristics of Geopolymer Foam Concrete and Their Impact on the Compressive Strength and Modulus
}

\author{
Zuhua Zhang* and Hao Wang* \\ Centre for Future Materials, University of Southern Queensland, Toowoomba, QLD, Australia
}

\section{OPEN ACCESS}

Edited by:

Wenhui Duan,

Monash University, Australia

Reviewed by:

Ionut Ovidiu Toma

Gheorghe Asachi Technical University of laşi, Romania

Lin Liu,

Hohai University, China

${ }^{*}$ Correspondence:

Zuhua Zhang

zuhua.zhang@usq.edu.au; Hao Wang

hao.wang@usq.edu.au

Specialty section: This article was submitted to

Structural Materials,

a section of the journal

Frontiers in Materials

Received: 20 June 2016 Accepted: 26 July 2016 Published: 10 August 2016

Citation:

Zhang $Z$ and Wang $H$ (2016)

The Pore Characteristics of

Geopolymer Foam Concrete and Their Impact on the Compressive

Strength and Modulus. Front. Mater. 3:38.

doi: 10.3389/fmats.2016.00038
The pore characteristics of geopolymer foam concretes (GFCs) manufactured in the laboratory with $0-16 \%$ foam additions were examined using image analysis (IA) and vacuum water saturation techniques. The pore size distribution, pore shape, and porosity were obtained. The IA method provides a suitable approach to obtain the information of large pores, which are more important in affecting the compressive strength of GFC. By examining the applicability of the existing models of predicting compressive strength of foam concrete, a modified Ryshkevitch's model is proposed for GFC, in which only the porosity that is contributed by the pores over a critical diameter $(>100 \mu \mathrm{m})$ is considered. This "critical void model" is shown to have very satisfying prediction capability in the studied range of porosity. A compression-modulus model for Portland cement concrete is recommended for predicting the compression-modulus elasticity of GFC. This study confirms that GFC have similar pore structures and mechanical behavior as those Portland cement foam concrete and can be used alternatively in the industry for the construction and insulation purposes.

Keywords: alkali-activated cement, geopolymer, foam concrete, pore size, porosity, compressive strength, compression modulus

\section{INTRODUCTION}

Foam concrete is usually manufactured by introducing air, either by chemical reaction or mechanical mixing, into Portland cement paste or mortar (with normal sand or lightweight aggregates) to form a homogeneous porous structure. Because of the large volume of voids, foam concrete offers better thermal insulation property than normal dense concrete. In recent years, the increasing public concern of building energy efficiency and embodied energy of construction materials has driven the rapid research and development of foam concretes. The utilization of foam concretes in China has exceeded 35 million $\mathrm{m}^{3}$ in 2015 , of which $\sim 80 \%$ were used as/for insulation wall panel and insulation layer of roof; the production of foam concrete is increasing at an annual rate of $20 \%$ in China [China Concrete \& Cement-Based Products Association (CCPA) Report, 2016].

Geopolymer foam concrete (GFC) is the most recently developed foam concrete with the concept of using geopolymer as an alternative binder to replace Portland cement (Zhang et al., 2014b). Geopolymer is manufactured by alkali-activation of reactive aluminosilicate solids, usually the industrial by products, such as fly ash and slag, and other types of raw materials (particularly the heated kaolin). The alkali activators are normally sodium/potassium hydroxide, sodium/potassium silicate solutions, and their mixtures. After the activation and reaction at ambient to elevated 
temperatures, hardened geopolymers can exhibit similar (sometimes superior) mechanical properties as hardened Portland cement. Because this activation process avoids high temperature calcination of limestone and clinker milling, geopolymer is much more sustainable than Portland cement, in terms of $\mathrm{CO}_{2}$ emissions and embodied energy (Duxson et al., 2007; Stengel et al., 2009; McLellan et al., 2011). Therefore, the application of GFC can combine the advantages of foam concrete and geopolymer technology, and provide the opportunity to reduce the environmental footprint of construction materials from manufacturing to operation stages. This has been attracting many researchers in the past decade (Zhang et al., 2014b).

Pore characteristic (size, volume, and connectivity) of foam concrete is the most important factor that governs the compressive strength, thermal conductivity, and permeability. The pores in foam concrete, either Portland cement based or geopolymer based, consist of interlayer pore/space, gel pore, capillary pore, and air void, and the sizes of these pores vary from nanometer scale to millimeter scale. For example, in Portland cement foam concrete, the cement binder will have (1) interlayer pores/space in calcium silicate hydrates with width smaller than $1 \mathrm{~nm}$ (this type of pores may be not considered in some definition), (2) gel pores between calcium silicate hydrates with width between 1 and $10 \mathrm{~nm}$, and (3) capillary pores between gel clusters with width larger than $10 \mathrm{~nm}$ (Pinson et al., 2015), in addition to the introduced voids with width from several micrometers to 1-2 mm (Nambiar and Ramamurthy, 2007a). The total volume of pores, namely porosity, correlates with density and plays an important role that affects the compressive strength of foam concrete (Matusinović et al., 2003). In this study, the connectivity of pores refers the interaction of introduced voids, and this characteristic determines the strength and permeability of foam concrete. The connectivity of pores depends on the foaming methods and the use of different foaming agents. The use of alumina powder and hydrogen peroxide can generate a GFC with relatively lower connected pores than using surfactant, at even a lower density (more voids) conditions (Masi et al., 2014); the use of a combination of oleic acid and $\mathrm{H}_{2}$ solution results in more connected pores, which can significantly increase the fluid transportation rate through the geopolymer foam (unpublished data by the authors). The high connectivity of individual fine pores leads to large open and interacted pores, which lower the compressive strength but can be desirable for other purposes (Zhang et al., 2016).

There have been numerous studies on the pore structure of Portland cement foam concretes and the effect of porosity and pore size on their compressive strength and other properties (Kearsley and Wainwright, 2001; Nambiar and Ramamurthy, 2007a,b; Mydin and Wang, 2012). Several models have been developed to describe the relationship between porosity (or density) and compressive strength for Portland cement systems; however, whether those existing models [such as the Bashin's and Ryshkevitch's models for compressive strength correlation (Kearsley and Wainwright, 2002)] suit GFC or not is unknown. Very few models also have been developed for GFC due to the complexity of geopolymer formulation (binder type, with or without fillers), further research on other systems are required to comprehensively understand the effect of pore characteristics, thus, detail them in the manufacturing.

The aim of this study is to investigate the pore structure of fly ash-slag blended GFC and the relationship with mechanical properties. Blending fly ash and slag together as raw materials is a common practice of geopolymer manufacturing in industry, as the incorporation of slag can accelerate the setting at ambient temperatures and the compressive strength development (Yang et al., 2012; Lee and Lee, 2013; Gao et al., 2015). In this study, it is also desirable to use slag to partially replace fly ash to increase the early age strength, instead of using excessive alkalis, particularly given the potential of efflorescence (Zhang et al., 2014a).

\section{MATERIALS AND METHODS}

\section{Sample Preparation}

Geopolymer foam concrete samples were prepared following the procedure shown in Figure 1. The activation solutions included a $12 \mathrm{M} \mathrm{NaOH}$ solution and a sodium silicate solution (PQ Australia D-Grade $\left.{ }^{\mathrm{Tm}}\right)$. The amounts of the $\mathrm{NaOH}$ and sodium silicate solutions used were 0.155 and 0.24 in mass ratio to the solid raw materials, which were blends of $70 \%$ fly ash and $30 \%$ slag. The fly ash was sourced from Tarong power station (QLD, Australia), graded as Class F, and the slag was obtained from Cement Australia Pty

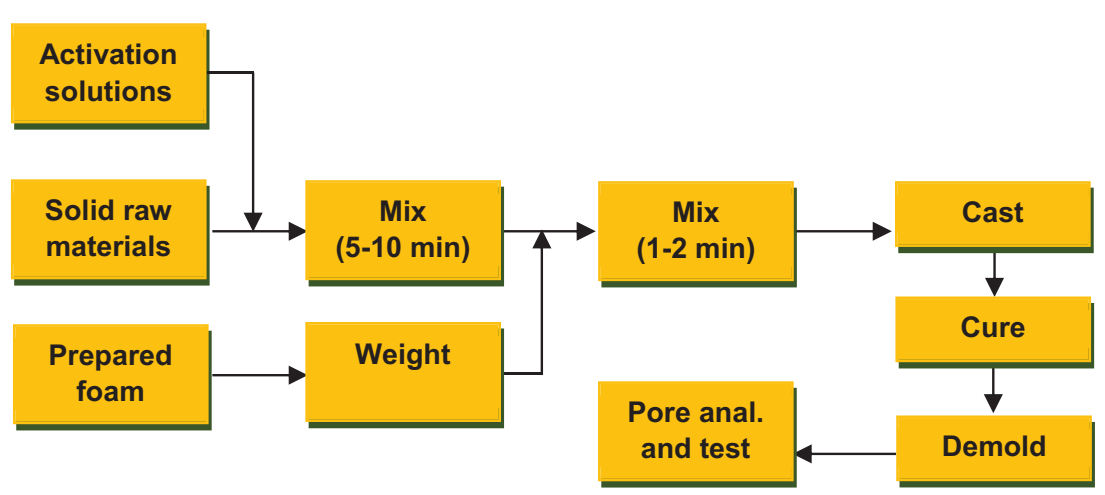

FIGURE 1 | GFC laboratory manufacturing process. 
TABLE 1 | Compositions of solid raw materials, mass $\%$.

\begin{tabular}{|c|c|c|c|c|c|c|c|c|c|c|c|}
\hline Materials & $\mathrm{SiO}_{2}$ & $\mathrm{Al}_{2} \mathrm{O}_{3}$ & $\mathrm{CaO}$ & MgO & $\mathrm{K}_{2} \mathrm{O}$ & $\mathrm{Na}_{2} \mathrm{O}$ & $\mathrm{Fe}_{2} \mathrm{O}_{3}$ & $\mathrm{P}_{2} \mathrm{O}_{5}$ & $\mathrm{SO}_{3}$ & $\mathrm{TiO}_{2}$ & LOI $^{a}$ \\
\hline Fly ash & 72.1 & 24.7 & 0.1 & 0.2 & 0.5 & $\leq 0.1$ & 1.2 & $\leq 0.1$ & $\leq 0.1$ & 1.4 & 0.4 \\
\hline Slag & 33.3 & 14.6 & 41.7 & 6.1 & 0.3 & 0.2 & 0.8 & 0.2 & 0.6 & 0.6 & 0.5 \\
\hline
\end{tabular}

aOI is loss on ignition.

Ltd. The chemical compositions of the activations solutions and solid raw materials are given in Table $\mathbf{1}$.

The solid raw materials were dry mixed in a cement mortar mixer, followed by adding the $\mathrm{NaOH}$ solution and sodium silicate solution. The mixing will be $5-10 \mathrm{~min}$; at the meanwhile, foam was generated using an air pressure foam generator, weighed, and immediately transferred at the end of paste mixing. Considering the water content introduced by foam (with mass ratios to solid materials of $0,1.3,3.3,5,6.7,10,13$, and $16 \%$ ), additional water (0-10\%) was added during the paste mixing, thus, to obtain a consistent mixture with high flowability (as determined by a mini slump) and little variation of compositions. The homogeneous foamed slurry was cast in $\varphi 53 \times 105 \mathrm{~mm}$ plastic molds, sealed with plastic film wrap, cured at $40^{\circ} \mathrm{C}$ for 1 day, aged for 27 days at ambient conditions, and then demolded for testing and characterization. The curing temperature $40^{\circ} \mathrm{C}$ was optimized according to the mixture. At this temperature, there is little volume change during the curing period, while high or low temperatures can cause large expansion or sink of the fresh slurry.

\section{Pore Analysis}

The characterization of air voids was also carried out with an image analysis (IA) system consisting of an Olympus optical microscopy and the Analysis-FIVE software. The sample preparation was referenced the method proposed by Nambiar and Ramamurthy (2007a). Specifically, the oven-dried specimens were first polished, cleaned with compressed air to blow away the losing particles in the open air voids, coated with black ink, and allowed to dry for several hours. White talc powder was then spread on the black surface and slowly filled into the air voids by vibrating the specimens and pressing with a flat glass slide. The excess powder was wiped away with the edge of a razor blade and then with normal office adhesive tape, which can remove the powder lying on the binder while retain the powder in voids unaffected. This method attained a surface with sharp and easily distinguishable boundaries of the air voids and matrix by their high color contrast under optical microscopy. As the objective was to observe the air voids of GFC, a low magnification of $20 \times$ was selected. Each specimen has 20 images captured to analyze parameters of pore size and shape factor of all identified voids. The shape factor is determined by $\mathrm{SF}=$ (perimeter $)^{2} /(4 \pi$-area).

The porosity of GFC was determined by a vacuum saturation method (Kearsley and Wainwright, 2002). Usually, the test sample should be a core taken from a large specimen, so as to avoid the possible effects of the surface on water absorption. In this study, the surfaces of specimens were, therefore, polished with sand paper. After measuring the sizes and oven-dried weight $\left(m_{\mathrm{dry}}\right)$ at $105^{\circ} \mathrm{C}$, specimens were evacuated under a vacuum of $80-100 \mathrm{kPa}$ for 2 days and then boiled water was sucked in until all specimens were immersed. The immersed system was kept under the negative pressure for 1 day. By this process, it was believed that all of the air bubbles have been removed from the specimens as well as that in the boiled water. After the vacuum, specimens were removed from the water and weighed $\left(m_{\text {sat }}\right)$. The water saturation porosity was calculated using this formula, $P=\left(m_{\text {sat }}-m_{\text {dry }}\right) /(\rho v)$, in which $\rho$ is the density of water, $v$ is the volume of the polished specimen.

\section{Mechanical Measurements}

The compressive strength of the cylindrical $(\varphi 53 \times 105 \mathrm{~mm})$ samples was measured at the age of 28 days on an MTS universal mechanical testing instrument at a loading speed of $0.5 \mathrm{~mm} /$ min. The stress-strain were recorded to calculate the modulus of compression elasticity by using the range between 20 and $60 \%$ of maximum stress of each curve.

\section{RESULTS AND DISCUSSION}

\section{Pore Size and Distribution}

Typical binarized images of GFC with $0-16 \%$ foam addition are shown in Figure 2. The pore and voids are in the diameters from several micrometers to over $1000 \mu \mathrm{m}$. It is acknowledged that one of the limitations of the imaging method is that only large pores can be effectively characterized. In this study, the smallest distinguishable pores are $24.62 \mu \mathrm{m}^{2}$, and the corresponding equivalent circle diameter (ECD) is $5.60 \mu \mathrm{m}$, which is much smaller than the objective macropores $(>50 \mu \mathrm{m})$ in the analysis of OPC foam concretes (Nambiar and Ramamurthy, 2007a).

In the solid geopolymer sample GFC0, pores that are larger than $5.6 \mu \mathrm{m}$ are also observed. Two possible reasons may cause these large pores in solid samples. The first reason is the introduction of air voids during mixing. This is inevitable under ambient conditions (vacuum mixing could avoid such type of pores). The second possible reason is that the unreacted fly ash particles in the hollow structure fall off from the shell during sampling. However, whether formed because of mixing or the detachment of unreacted particles, these pores are all weak regions in the structure, and have impact on the mechanical properties.

Figure 3 further presents the frequency of the detected pores as a function of their size ranges. In the geopolymer GFC0, 85\% of the detected pores are smaller than $100 \mu \mathrm{m}$. With an increased dosages of foam, the number of pores that are larger than $100 \mu \mathrm{m}$ increases. However, when foam addition is higher than $10 \%$, the frequency of pores $<100 \mu \mathrm{m}$ increases significantly. This is not because the number of fine pores becomes larger but because of the increased pore interruption, which is the total number of pores decreases (which is evident in Figures 2G,H). As a result, 

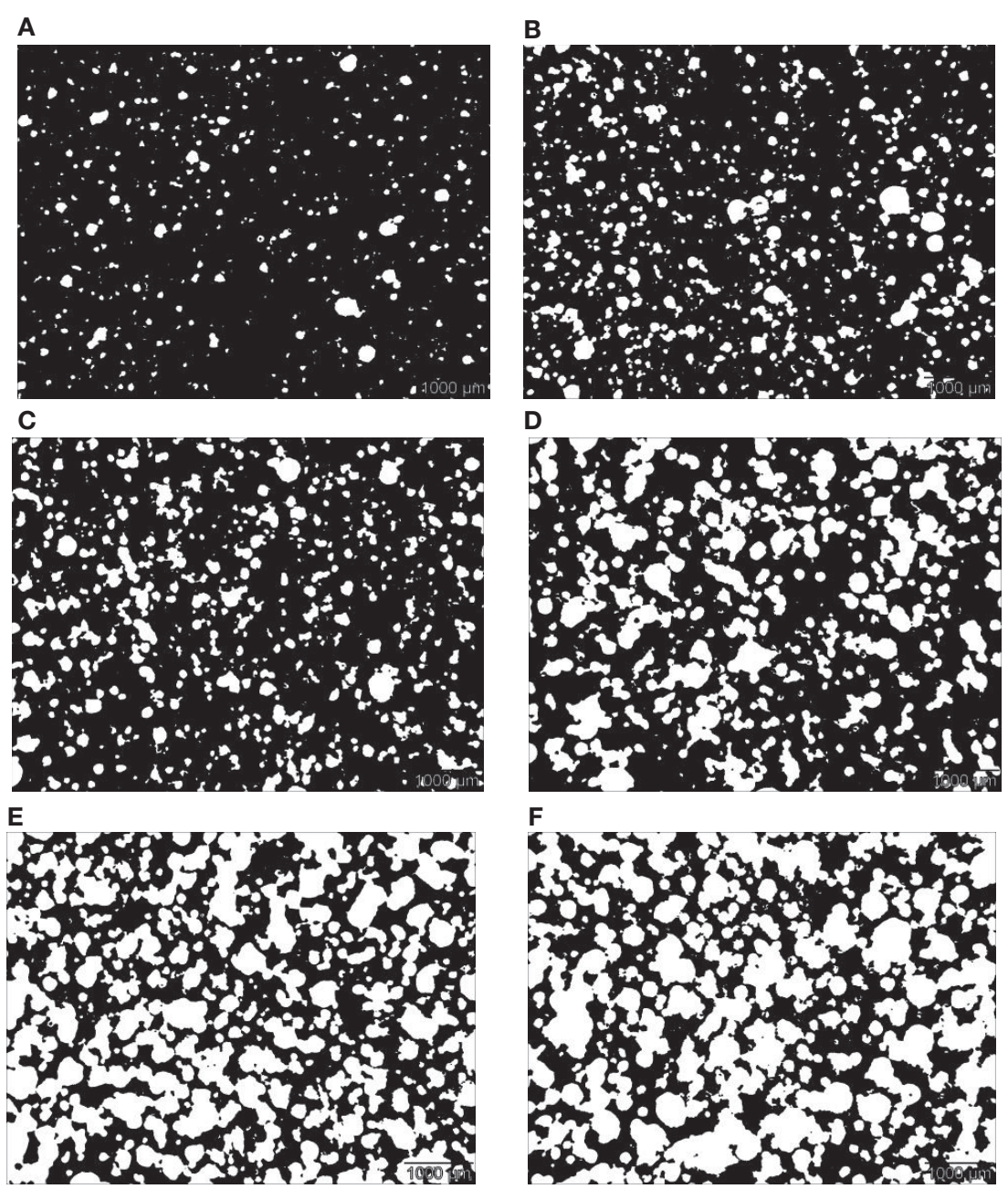

D
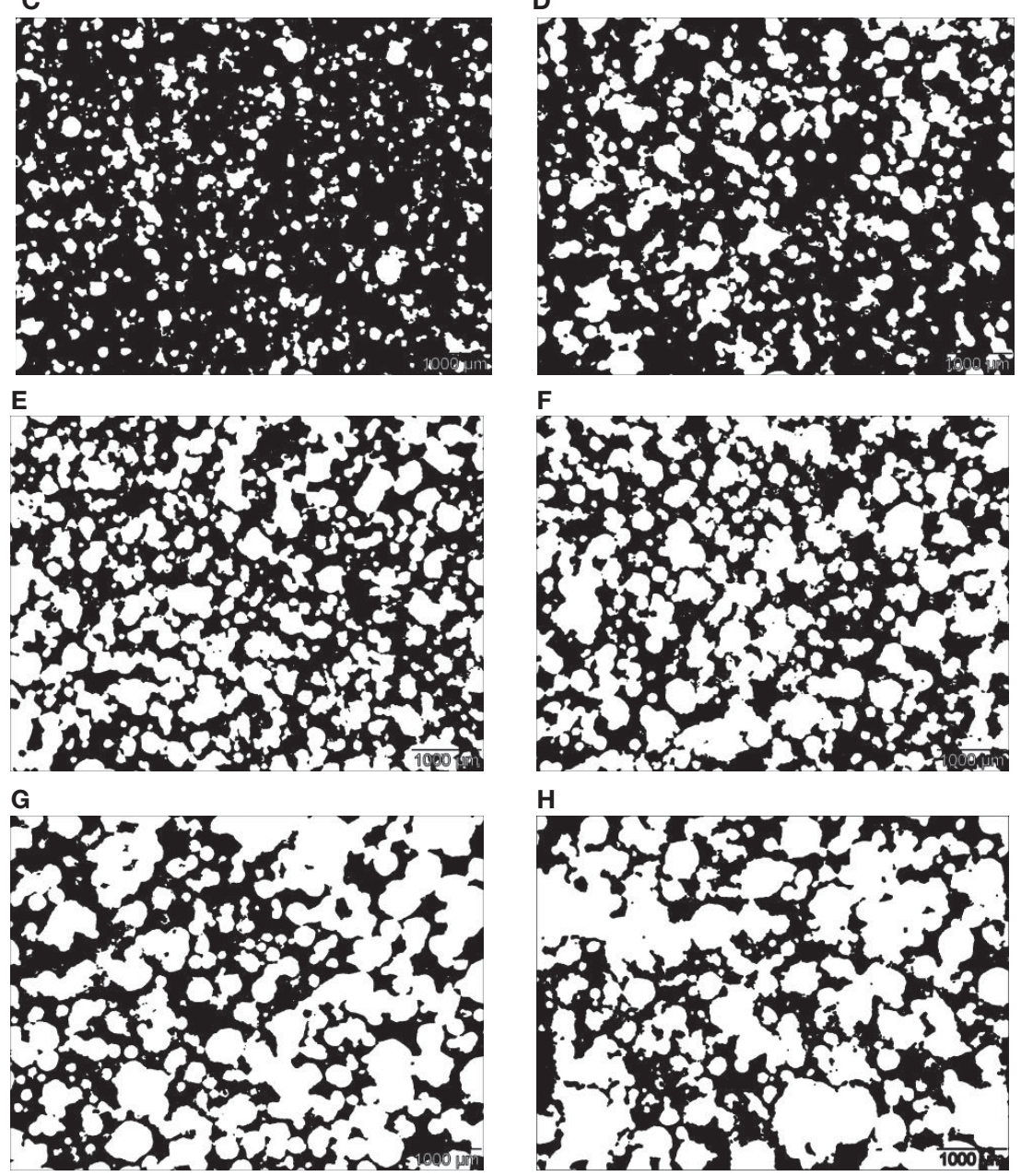

FIGURE 2 | Typical IA images of GFCs with $0 \%$ (A), 1.3\% (B), 3.3\% (C), 5\% (D), $6.7 \%$ (E), 10\% (F), 13\% (G), and 16\% (H) of foam addition in respect of solid raw materials. The white areas are pores and the black areas are geopolymer binder. The scale bar is $1000 \mu \mathrm{m}$.

the total volume of large bubbles increases, which can be reflected by the distribution of area fraction of pores, as shown in Figure 4.

As the foam dosages increases, large pores occupy more space. The pores larger than $1000 \mu \mathrm{m}$ occupy the major area $(>50 \%)$ in GFC10, GFC13, and GFC16. There is an overall trend shown in Figure 4 that the actual shape of the trend lines changes at a foam dosage of about $5 \mathrm{wt} . \%$. The absolute volume of pores in the tested size range decreases consistently when the dosage increases from
6.7 to 16 wt.\%. This indicates that when the foam dosage is higher than around $5 \mathrm{wt} . \%$, only a small fraction of the finer air bubbles remains isolated. It would suggest that many of the bubbles tend to coalesce and form larger voids.

As the pores are randomly distributed in foams, and the cross sections for IA are also random, if it is assumed that the pore (or void) space in the two-dimensional image can be representative for pores in the three-dimensional block, the area fraction can be 

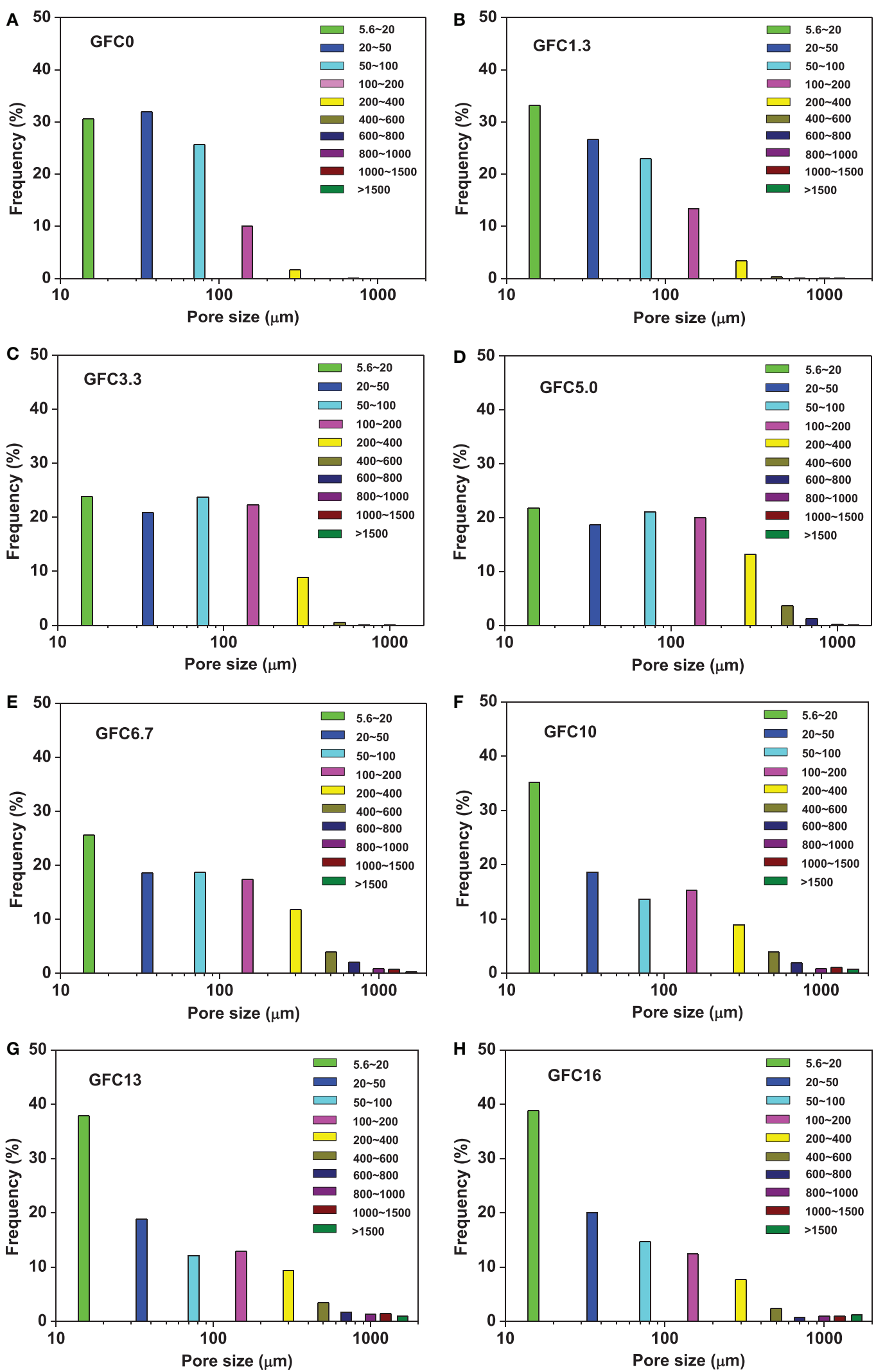

FIGURE 3 | Frequency of detected pores (or voids) in GFCs with $0 \%(A), 1.3 \%(B), 3.3 \%(C), 5 \%$ (D), $6.7 \%$ (E), 10\% (F), 13\% (G), and 16\% (H) of foam addition in respect of solid raw materials. 
regarded as porosity of the detectable pores by IA. This point is supported by the porosity measurements of pervious concretes (Deo and Neithalath, 2010). The image number and mean porosity of each sample are summarized in Table 2, with the calculated $\mathrm{SD}$ and coefficients of variation. The distribution of such porosity as a function of foam dosage is shown in Figure 5.

From Table 2 and Figure 5, it is noted that the SDs of the total area fractions for each specimen are $<5 \%$. This shows the heterogeneous nature of the pore structure. Because of the difficulties of mixing solid-liquid-gas three phases and the segregation in casting process and setting, images that are taken from different parts of the sections may vary. In another study of pervious concretes with pore area fraction between 20 and 30\%, the IA method measured with an error of $\pm 6 \%$ (Sumanasooriya and Neithalath, 2009). The error is one of the limitations of the IA. In terms of the IA itself, the coefficients of variation of the measured porosity are relatively large at lower foam dosages, and this is mainly due to the relatively lower mean porosity. With porosity increases, the coefficients of variation decreases. GFC5.0 and GFC6.7 have the lowest coefficients of variation among the measured images, which means the most homogeneous pore size distribution.

\section{Pore Shape Factor}

As shown in Figure 2, when more foam is introduced, the pores become larger and more connected. When the foam dosage is

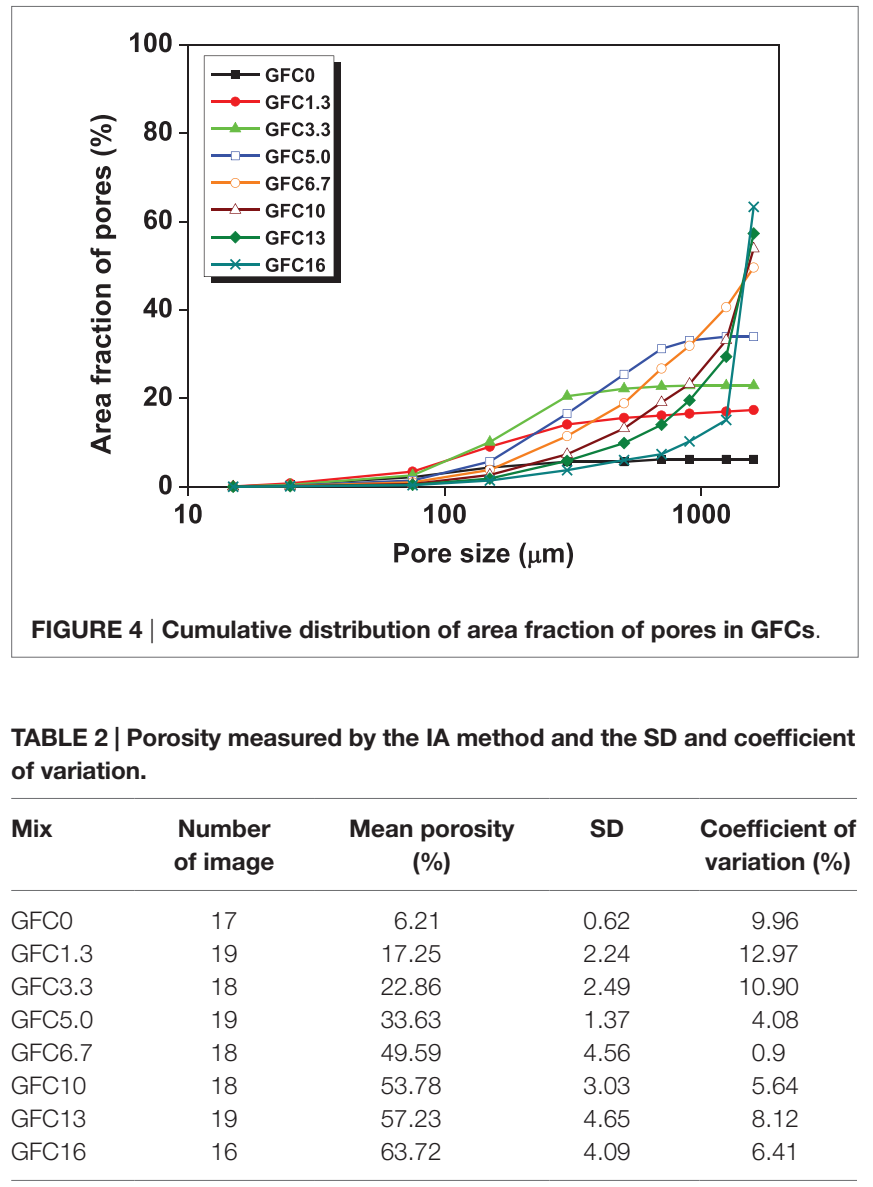

Each mixture has two samples analyzed. higher than $5 \%$, only a small number of pores remain fine and isolated. Many pores interconnect with each other on their "spherical" perimeter, forming large and irregular pores. To quantify this feature, the shape factor of each pore is determined, and plotted against their ECDs, as shown in Figure 6.

Although the over lapped plots make it challenging to distinguish the differences between the eight products at high shape factor region $(>0.4)$, it is still readable that samples with $>5 \%$ foam possess more pores larger than $500 \mu \mathrm{m}$. GFC13 and GFC16 have more irregular pores with shape factors below 0.1 and ECDs larger than $2000 \mu \mathrm{m}$, which means in these products, pores are connected and become millimeter size. Counting all of the determined pores, the average pore shape factor decreases from 0.814 in GFC0 to 0.695 in GFC6.7, and the corresponding pore size increases from 50.1 to $135.9 \mu \mathrm{m}$; however, the shape factor keeps relatively constant at about 0.7 in GFCs with higher foam dosages and the average pore size also keeps relatively constant. These average values are

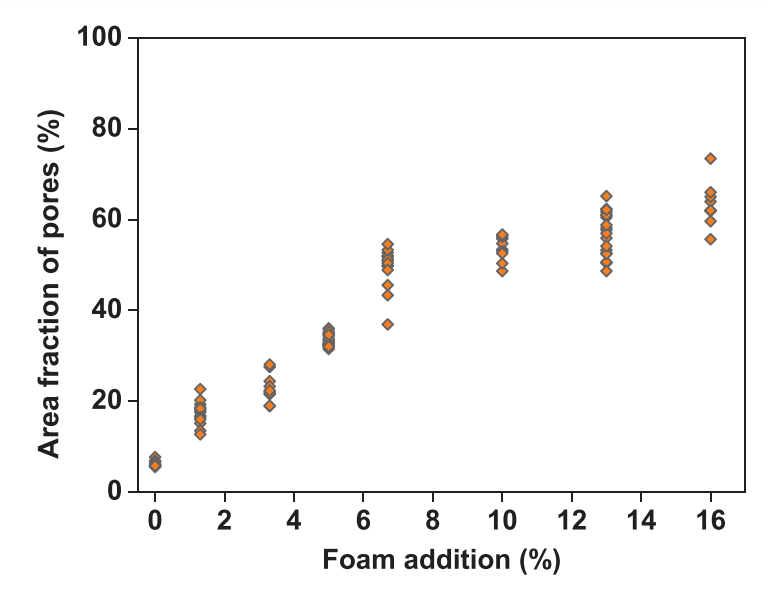

FIGURE 5 | Area fraction of pores in GFCs

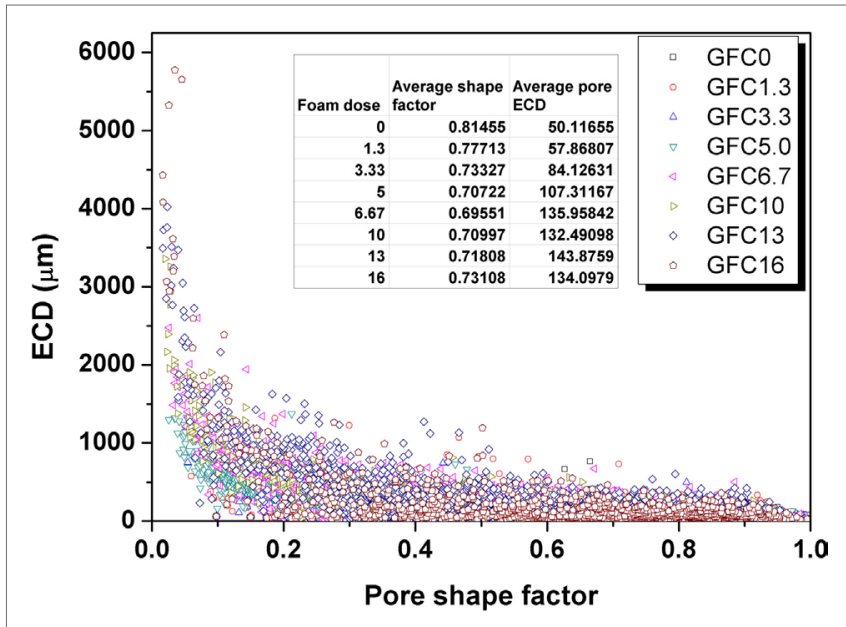

FIGURE 6 | Pore shape factor distribution and the relationship with pore sizes in GFCs. 
obtained by weighting the sum of shape factors or pore sizes over the total number of each sample. This seems conflict with the observation in Figure 2. The reason is that overall weighting does not consider the numbers of fine pores on the shape factor. There are only a few pores that have large sizes, such as $>2000 \mu \mathrm{m}$. To more accurately describe the shape factors and pore sizes, Figure 7 plots their average values by weighting the numbers of pores over certain ranges (as shown by icons in Figure 3).

It is noted that the pore shape factor has no direct relationship with foam dosages. The shape factor decreases in a roughly linear relation as function of the pore size. At the small pore size range, the pores are more cycle while at larger sizes, the pores become more irregular, which is due to the interconnection between pores. Nambiar and Ramamurthy (2007a) suggested that the shape of pores has no influence on the properties of foam concrete, as the air voids are approximately the same shape and independent of foam volume. The pore shape distribution of GFCs seems to follow the same trend as Portland cement foam concrete, that is, the average pore shapes keep constant as a function of dosage of foam or density.

\section{Porosity}

The total porosity $P$ as determined by water saturation method is given in Table 3, with comparison to the values by IA for large pores. As expected, the water saturation porosity is much higher than porosity determined by IA, which cannot count those pores

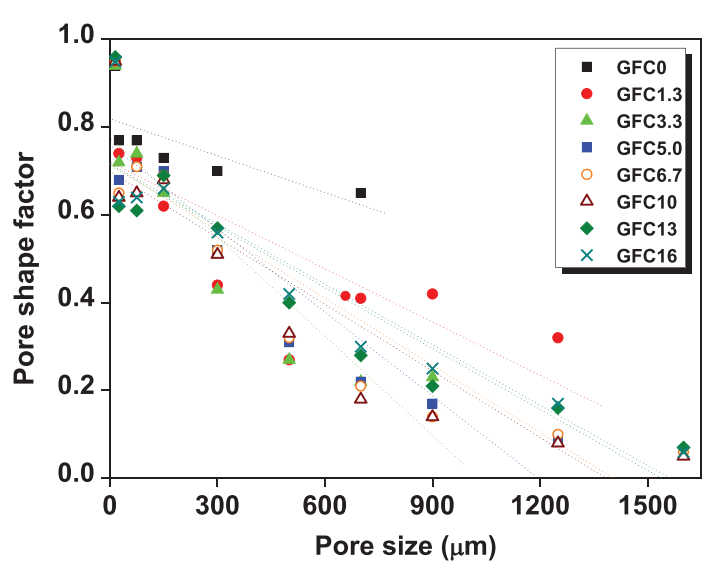

FIGURE 7 | Average shape factor of pores over averaged pore size.

TABLE 3 | Porosity by water saturation and pore volumetric proportion by IA.

\begin{tabular}{lcrrrrrrl}
\hline Foam content (\%) & 0 & 1.3 & 3.3 & 5.0 & 6.7 & 10 & 13 & 16 \\
$P-$ porosity by & 34.1 & 35.3 & 44.1 & 55.2 & 57.3 & 59.9 & 63.2 & 64.8 \\
$\begin{array}{l}\text { water saturation } \\
P_{1}-\text { porosity by }\end{array}$ & 6.2 & 17.4 & 22.9 & 34.0 & 49.6 & 53.8 & 57.4 & 63.1 \\
$\begin{array}{l}\text { IA, refers to pores } \\
>5.6 \mu \mathrm{m}\end{array}$ & & & & & & & & \\
$\begin{array}{l}P_{2}=P-P \\
\text { to pores }<5.6 \mu \mathrm{m}\end{array}$ & 27.9 & 17.9 & 21.2 & 21.2 & 7.7 & 6.1 & 5.8 & 1.7
\end{tabular}

with diameter smaller than $5.6 \mu \mathrm{m}$ in the matrix. As the water saturation method was performed under vacuum conditions and the matrix are porous, which allows water to easily penetrate, the porosity determined by this method is believed to be the true porosity. These pore features and porosity are critical factors that will govern the mechanical properties and other properties of foam concrete.

\section{The Relationship Between Pore Features and Compressive Strength}

Porosity has been used as a single parameter in Balshin exponential model and Ryshkevitch exponential model and their deriving models to predict the strength of Portland cement foam concretes (Kearsley and Wainwright, 2002). To examine the applicability of those existing models in relating porosity and compressive strength of GFCs, the determined porosity is used to fit the two basic models and it is noted that Ryshkevitch's model fits better than the Balshin's model, as indicated by the higher $R^{2}$ in Figure 8.

The fitting constants for the exponents for porosity $P$ are more close to those in the equations by Kearsley and Wainwright (2002), which means the porosity in affecting the compressive strength of GFCs in the similar way as in Portland cement concrete. If the correlation coefficient is considered, both of the two new relationships appear reasonable and useful. They indicate strong relationships between the compressive strength and the porosity of the GFCs. However, as shown in Figure 8, the porosities are in the range from 0.55 to 0.7 , the models fit well with the observed values; but as porosity shifts toward lower region, the difference between predicted and observed values becomes larger. The large difference in the low porosity region is expected to be due to the effects of pore size distribution on the strength being omitted in the two models. It is generally agreed that large pores or voids are more harmful to the structures than small pores in cement-based materials (Neville, 2011).

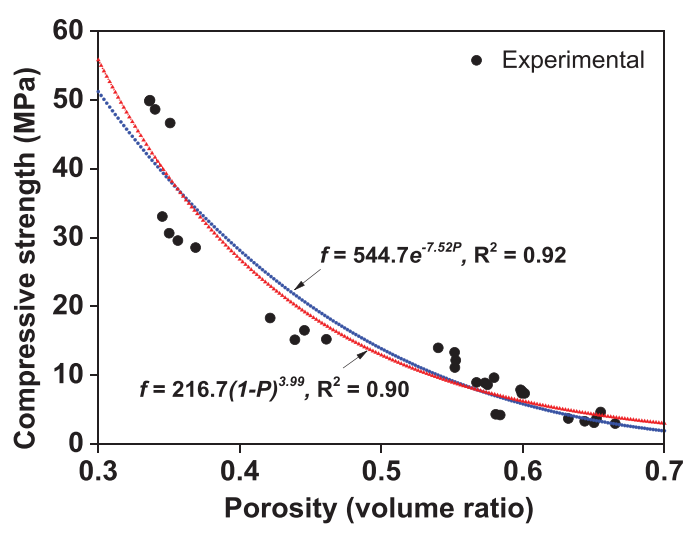

FIGURE 8 | The fitting correlations of compressive strength $f$ and porosity $\boldsymbol{P}$ for Balshin exponential model $\left(R^{2}=0.90\right)$ and Ryshkevitch exponential model $\left(R^{2}=0.92\right)$. 
Considering the potential effects of pore size, two new models based on Ryshkevitch's and Balshin's models are proposed as follows:

$$
\begin{gathered}
\text { Model 1: } f_{c}=A \times e^{a \cdot p_{1}}+B \times e^{b \cdot p_{2}} \\
\text { Model 2: } f_{c}=C \times\left(1-p_{1}\right)^{c}+D \times\left(1-p_{2}\right)^{d}
\end{gathered}
$$

In Models 1 and 2, the volume of small pores $(<5.6 \mu \mathrm{m})$ and the volume of large pores $(>5.6 \mu \mathrm{m})$ are treated separately (Table 3). The empirical constants $a, b$ in Eq. 1, and $c, d$ in Eq. 2 indicate the relative impacts of large pores and small pores on the strength; $A, B, C$, and $D$ are fitting constants. The regression results are given in Table 4.

The correlation coefficient and $R^{2}$ both increase in the new models compared to those original Ryshkevitch's and Balshin's models in Figure 8. It is clear that treating different size pores separately is helpful in improving the fitting accuracy. In other words, the pores with different sizes contribute differently to the mechanical property of foam concrete. The second parts of the two models both have very high exponents, which mean that the terms of small pore in the two equations contribute nearly zero to $f_{c}$. The porosity of large pores correlates with the strength very well, while the effect of small pores is very limited. Considering this fact, Model 3 based on Ryshkevitch's model is proposed to only treat large pores with critical diameter and the regression equation is shown below:

$$
\text { Model 3: } f_{c}=62.33 e^{-4.307 p_{c}}
$$

In which $P_{c}$ refers to the porosity of pores larger than $100 \mu \mathrm{m}$. This size is selected from the analysis of pore size distribution over area, as shown in Figure 4, and it was selected by Schober (2011) to allocate the lower limited of air or gas pores (also regarded as macropores) in OPC foam concretes, and also used by Hlaváček et al. (2015) as a critical size for fly ash-based GFC using aluminum powder as foaming agent. The proposed critical pore model has $R^{2}$ of 0.98 and a correlation coefficient of 0.99 . Using the porosity of critical pores can precisely correlate with the strength of GFC. It confirms that for foam concrete, the large pore model gives a satisfying and better fitting than using the whole range of pores or total porosity (Nambiar and Ramamurthy, 2007a).

\section{Modulus of Elasticity in Compression}

The modulus of elasticity is one of the key mechanical properties of concrete that determine the strain and creep behavior. The relationship between strain and stress over their full range is of vital importance in structural design. Understanding compression elastic modulus of GFCs is an important aspect to develop them for structural or semi-structural applications.

TABLE 4 | The strength-porosity relationship of GFCs with consideration of separated contributions of large pore $\boldsymbol{P}_{1}$ and small pore $\boldsymbol{P}_{2}$.

\begin{tabular}{llcc}
\hline Model & Regression equations & $\boldsymbol{R}^{\mathbf{2}}$ & $\begin{array}{c}\text { Correlation } \\
\text { coefficient }\end{array}$ \\
\hline Model 1 & $f_{c}=61.55 e^{-4.396 p_{1}}-5.28 e^{-280.15 p_{2}}$ & 0.97 & 0.99 \\
Model 2 & $f_{c}=56.11\left(1-p_{1}\right)^{3.07}-10.25\left(1-p_{2}\right)^{207.50}$ & 0.97 & 0.98
\end{tabular}

Figure 9 shows the representative strain-stress curves of the GFCs manufactured with different quantities of foam addition.

Compared to the typical stress-strain curves of solid Portland cement concrete (Neville, 2011) and geopolymer concretes (Hardjito, 2005), the geopolymer binder (0\%) exhibits much higher strain under the same compression loading. This is because of the absence of aggregates in the binder. In comparison with Portland cement foam concrete (Mydin and Wang, 2012), the GFC at a similar density also shows higher strain. More importantly, the deformation under loading is more linear as shown by the stress-strain curves, which means that they are in elastic state below maximum loading.

The modulus of elasticity decreases with an increase in the foam content or porosity. Several models have been developed to correlate the modulus of elasticity with compressive strength for aerated concretes (Narayanan and Ramamurthy, 2000). Two general forms of the models are shown below:

$$
\begin{gathered}
E_{c}=a \cdot f_{c}^{b} \\
E_{c}=a \cdot \rho \cdot f_{c}^{0.5}
\end{gathered}
$$

in which, $a$ and $b$ are fitting constants, $\rho$ is density (usually ovendried density, $\mathrm{kg} / \mathrm{m}^{3}$ ), $f_{c}$ is compressive strength, MPa.

Equation 4 uses the compressive strength as the sole independent parameter. Equation 5 is recommended by the CEB Manual of Design and Technology (1978) for autoclaved aerated concrete, where the constant $a$ usually ranges from 1.5 to 2.0. A model that can be regarded as a modified CEB model has been developed to describe the modulus of elasticity of EPS lightweight concretes (Saradhibabu et al., 2005):

$$
E_{c}=a \cdot \rho^{b} \cdot f_{c}^{c}
$$

in which, $a$ varies from 0.043 to $1.146, b$ is in a range of $1.1-1.53$ and $c$ usually equals to 0.25 or 0.5 according to different systems (Saradhibabu et al., 2005).

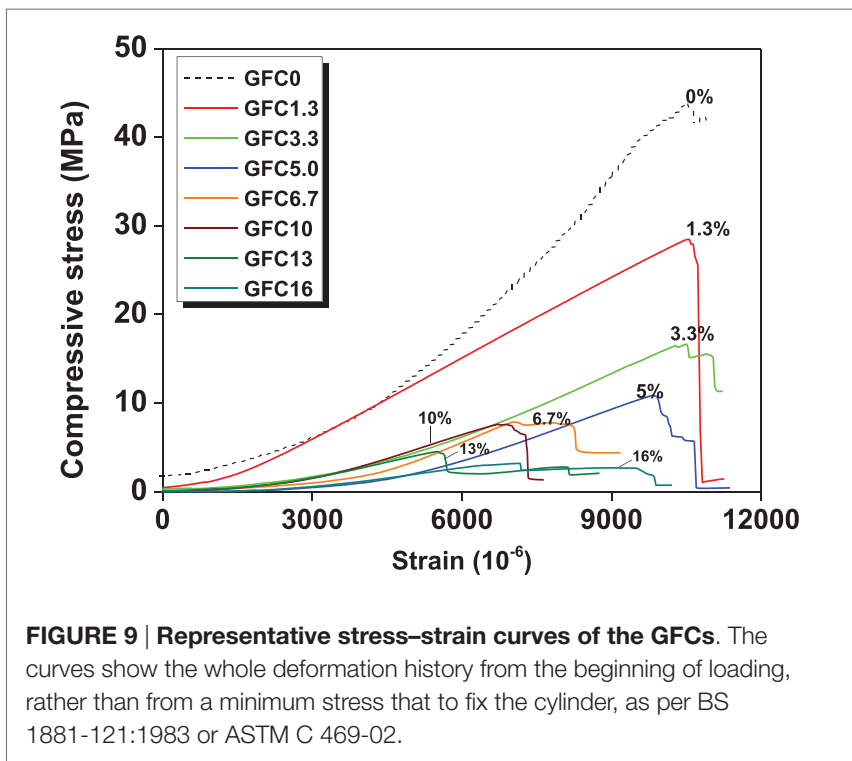




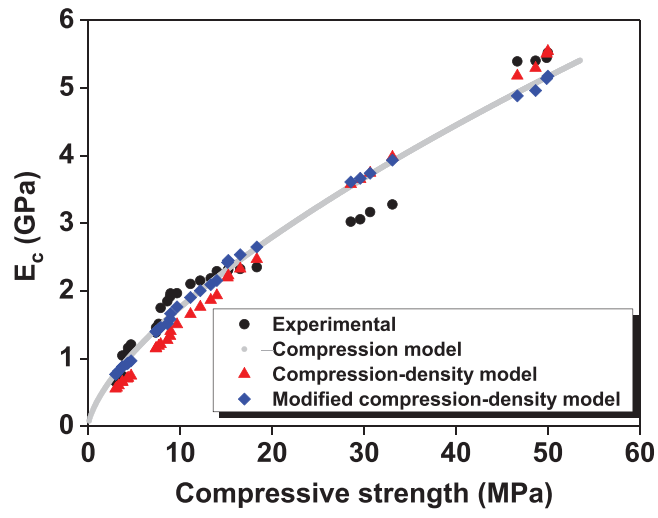

FIGURE 10 | The relationship between the modulus of the GFCs and compressive strength.

TABLE 5 | The regression equations of models predicting modulus of elasticity.

\begin{tabular}{lccc}
\hline Model & \multicolumn{1}{c}{ Equations } & $\boldsymbol{R}^{\mathbf{2}}$ & $\begin{array}{c}\text { Correlation } \\
\text { coefficient }\end{array}$ \\
\hline $\begin{array}{l}\text { Compression model } \\
E_{c}=0.3743 f_{c}^{0.671}\end{array}$ & 0.95 & 0.98 \\
$\begin{array}{l}\text { Compression-density } \\
\text { model }\end{array}$ & $E_{c}=0.561 \times 10^{-3} \rho \cdot f_{c}^{0.5}$ & 0.92 & 0.96 \\
$\begin{array}{l}\text { Modified compression- } \\
\text { density model }\end{array}$ & $E_{c}=0.902 \times 10^{-3} \rho \cdot f_{c}^{0.361}$ & 0.94 & 0.97 \\
& & &
\end{tabular}

To obtain the relationship between the compressive strength and density, and the modulus of elasticity of GFCs, these three models are all examined by fitting with observed data, as shown in Figure 10 and Table 5.

In general, all of the three models give acceptable predicting capabilities over the testing range. Among them, the compression model with the compressive strength as the sole variable has the best fitting result, in terms of the highest $R^{2}$. At the compressive strength of $6 \mathrm{MPa}$, the predicted modulus is $1.24 \mathrm{GP}$, which is a much higher than the measured value of 0.88 (0.14) GPa of the alumina powder foamed alkali-activated fly ash GFC (Hlaváček et al., 2015), which is probably due to the finer pore structure and also the stronger binder of the GFC in this study. All these results suggest that GFCs exhibit similar compression-deformation as Portland cement foam concrete, and can be alternatives in both non-structural and semi-structural applications.

\section{REFERENCES}

CEB Manual of Design and Technology. (1978). Autoclaved Aerated Concrete. New York: The Construction Press.

China Concrete \& Cement-Based Products Association (CCPA) Report. (2016). The Development and Progress of Foam Concrete in 2015. http://www.ccpa.com. $\mathrm{cn} / \mathrm{ccpa} /$ content/0-8287468076500.html

Deo, O., and Neithalath, N. (2010). Compressive behaviour of pervious concretes and a quantification of the influence of random pore structure features. Mater. Sci. Eng. 528, 402-412. doi:10.1016/j.msea.2010.09.024

\section{CONCLUSION}

Geopolymer foam concretes with a wide range of densities were successfully manufactured by mixing alkali-activated fly ash-slag blend (70/30) with $0-16 \%$ preformed foam. Both pore features and mechanical properties of the GFCs were investigated in this study. The pore size of GFC depends on the foam dose. The pore size distribution in GFC affects the compressive strength to a large extent, particularly at high porosity. The pore shape, on the other hand, keeps relatively constant as a function of dosage of foam or density, which has little or indirect effect on their mechanical properties. The verification on the Ryshkevitch's and Balshin's models and their modified variants, which considers small pores and large pores separately, demonstrates that the large pores have a significant effect on the compressive strength. Based on this, a new model is developed, called the "critical void model," which only concerns the porosity of critical size pores $(>100 \mu \mathrm{m})$. From the empirical fitting, a simple compressionmodulus model is recommended for predicting the modulus of elasticity in compression.

From the findings in this study, it is reasonable to conclude that GFC can be a greener alternative to Portland cement foam concrete for construction and insulation applications. However, because the large pores (mainly large voids) determine the compressive strength to a large extent, also the high viscosity of the paste, two important guidelines for foam concrete manufacturing can be extracted: (1) foaming agents, either for pre-forming method or chemical mixing method, should be able to generate fine bubbles; (2) the fine air bubbles introduced into the paste should be kept stable during mixing to avoid the formation of large pores. This might be able to achieve by introducing foam stabilizer and adjusting the setting behavior of geopolymer paste.

\section{AUTHOR CONTRIBUTIONS}

ZZ designed experiments, collected and analyzed data, interpreted results, and drafted the manuscript. HW contributed to experimental design and result discussion.

\section{FUNDING}

We thank partial funding for this work provided by the Australian Research Council Linkage Program, and the top-up scholarship by Halok Engineering.

Duxson, P., Provis, J. L., Lukey, G. C., and Van Deventer, J. S. J. (2007). The role of inorganic polymer technology in the development of 'green concrete'. Cement Concr. Res. 37, 1590-1597. doi:10.1016/j.cemconres.2007.08.018

Gao, X., Yu, Q., and Brouwers, H. J. H. (2015). Properties of alkali activated slag fly ash blends with limestone addition. Cement Concr. Compos. 59, 119-128. doi:10.1016/j.cemconcomp.2015.01.007

Hardjito, D. (2005). Studies on Fly Ash-Based Geopolymer Concrete. Ph.D. thesis. Curtin University of Technology.

Hlaváček, P., Šmilauer, V., Škvára, F., Kopecký, L., and Šulc, R. (2015). Inorganic foams made from alkali-activated fly ash: mechanical, chemical and 
physical properties. J. Eur. Ceram. Soc. 35, 703-709. doi:10.1016/j.jeurceramsoc. 2014.08.024

Kearsley, E. P., and Wainwright, P. J. (2001). Porosity and permeability of foamed concrete. Cement Concr. Res. 31, 805-812. doi:10.1016/S0008-8846(01)00490-2

Kearsley, E. P., and Wainwright, P. J. (2002). Ash content for optimum strength of foamed concrete. Cement Concr. Res. 32, 241-246. doi:10.1016/ S0008-8846(01)00666-4

Lee, N. K., and Lee, H. K. (2013). Setting and mechanical properties of alkali-activated fly ash/slag concrete manufactured at room temperature. Constr. Build. Mater. 47, 1201-1209. doi:10.1016/j.conbuildmat.2013.05.107

Masi, G., Rickard, W. D. A., Vickers, L., Bignozzi, M. C., and van Riessen, A. (2014). A comparison between different foaming methods for the synthesis of light weight geopolymers. Ceram. Inter. 40, 13891-13902. doi:10.1016/j. ceramint.2014.05.108

Matusinović, T., Šipušić, J., and Vrbos, N. (2003). Porosity-strength relation in calcium aluminate cement pastes. Cement Concr. Res. 33, 1801-1806. doi:10.1016/ S0008-8846(03)00201-1

McLellan, B. C., Williams, R. P., Lay, J., Van Riessen, A., and Corder, G. D. (2011). Costs and carbon emissions for geopolymer pastes in comparison to ordinary portland cement. J. Clean. Prod. 19, 1080-1090. doi:10.1016/j. jclepro.2011.02.010

Mydin, M. O., and Wang, Y. C. (2012). Mechanical properties of foamed concrete exposed to high temperatures. Constr. Build. Mater 26, 638-654. doi:10.1016/j. conbuildmat.2011.06.067

Nambiar, E. K. K., and Ramamurthy, K. (2007a). Air-void characterisation of foam concrete. Cement Concr. Res. 37, 221-230. doi:10.1016/j.cemconres.2006. 10.009

Nambiar, E. K. K., and Ramamurthy, K. (2007b). Sorption characteristics of foam concrete. Cement Concr. Res. 37, 1341-1347. doi:10.1016/j.cemconres. 2007.05.010

Narayanan, N., and Ramamurthy, K. (2000). Structure and properties of aerated concrete: a review. Cem. Concr. Compos. 22, 321-329. doi:10.1016/ S0958-9465(00)00016-0

Neville, A. M. (2011). Properties of concrete, 5th Edn. London, UK: Pearson.

Pinson, M. B., Masoero, E., Bonnaud, P. A., Manzano, H., Ji, Q., Yip, S., et al. (2015). Hysteresis from multiscale porosity: modeling water sorption and shrinkage in cement paste. Phys. Rev. Appl. 3, 1-17. doi:10.1103/PhysRevApplied. 3.064009
Saradhibabu, D., Ganeshbabu, K., and Wee, T. (2005). Properties of lightweight expanded polystyrene aggregate concretes containing fly ash. Cement Concr. Res. 35, 1218-1223. doi:10.1016/j.cemconres.2004.11.015

Schober, G. (2011). "Porosity in autoclaved aerated concrete (AAC): a review on pore structure, types of porosity, measurement methods and effects of porosity on properties," in 5th International Conference on Autoclaved Aerated Concrete (Bydgoszcz, Poland: Cement-Wapno-Beton), Special Issue: 39-43, 351-359.

Stengel, T., Reger, J., and Heinz, D. (2009). "Life cycle assessment of geopolymer concrete - what is the environmental benefit?"', in Concrete Solutions 09: Proceedings of the 24th Biennial Conference of the Concrete Institute of Australia (Sydney).

Sumanasooriya, M. S., and Neithalath, N. (2009). Stereology - and morphology based pore structure descriptors of enhanced porosity (pervious) concretes. ACI Mater. J. 106, 429-438. doi:10.14359/51663143

Yang, T., Yao, X., Zhang, Z., and Wang, H. (2012). Mechanical property and structure of alkali-activated fly ash and slag blends. J. Sustain. Cement Base Mater 167-178. doi:10.1080/21650373.2012.752621

Zhang, Z., Li, L., He, D., Ma, X., Yan, C., and Wang, H. (2016). Novel self-supporting zeolitic block with tunable porosity and crystallinity for water treatment. Mater. Lett. 178, 151-154. doi:10.1016/j.matlet.2016.04.214

Zhang, Z., Provis, J. L., Reid, A., and Wang, H. (2014a). Fly ash-based geopolymers: the relationship between composition, pore structure and efflorescence. Cement Concr. Res. 64, 30-41. doi:10.1016/j.cemconres.2014.06.004

Zhang, Z., Provis, J. L., Reid, A., and Wang, H. (2014b). Geopolymer foam concrete: an emerging material for sustainable construction. Const. Build. Mater. 56, 113-127. doi:10.1016/j.conbuildmat.2014.01.081

Conflict of Interest Statement: The authors declare that the research was conducted in the absence of any commercial or financial relationships that could be construed as a potential conflict of interest.

Copyright $\odot 2016$ Zhang and Wang. This is an open-access article distributed under the terms of the Creative Commons Attribution License (CC BY). The use, distribution or reproduction in other forums is permitted, provided the original author(s) or licensor are credited and that the original publication in this journal is cited, in accordance with accepted academic practice. No use, distribution or reproduction is permitted which does not comply with these terms. 